\title{
Penerapan Sistem SCADA Dalam Perancangan Model Inferensi Logika Fuzzy Mamdani Pada Pembebanan Trafo Gardu Distribusi
}

\author{
Rahma Farah Ningrum ${ }^{\text {; }}$ Riki Ruli A. Siregar ${ }^{2}$; Darma Rusjdi $i^{3}$ \\ ${ }^{1,2,3}$ Institut Teknologi PLN, Cengkareng - Jakarta Barat, Indonesia \\ 1rahmafarah@itpln.ac.id
}

\begin{abstract}
The research objective of this study is to make a prototype of the SCADA system in the process control system and Fuzzy Mamdani logic model on the loading of microcontroller-based distribution substations. It can ease all the users of the Internet-based (IoT) based control and monitoring system. The main function of the applied SCADA is the application of the Fuzzy Mamdani logic method with the implication function using the MIN method in terms of telemetering by measuring the current and voltage values. While the telecontrolling aspect is in the process of recovery or turning on and off the distribution substation during interruption. As for the Telesignaling aspect when sending notification signal to activate the substation recovery process during interruptions. The Data Acquisition is available when storing SAIDI SAIFI data and storing the results of the monitored equipment. From the results of hardware and software testing, especially in system testing is that when the substation is turned off, the recovery process runs according to the initial scenario. After the relay substation is resumed, the data is stored following the downtime, uptime, lifetime duration, and data period.
\end{abstract}

Keywords: SCADA, Internet of Things (IoT), Fuzzy Mamdani, Telemetering, Telecontrolling, Telesignaling

\begin{abstract}
ABSTRAK
Tujuan penelitian ini membuat prototipe sistem SCADA dalam proses sistem kendali dan model logika Fuzzy Mamdani pada pembebanan trafo gardu distribusi berbasis mikrokontroller. Hasilnya adalaha sebuah sistem kendali dan pemantauan berbasis Internet of Things (IoT) yang dapat memudahkan para penggunanya. Fungsi utama SCADA yang diterapkan yaitu Penerapan metode logika Fuzzy Mamdani dengan fungsi implikasi menggunakan metode MIN pada Segi Telemetering dengan pengukuran nilai arus dan tegangan. Sedangkan Segi Telekontrolling terdapat pada proses recovery atau menghidupkan dan mematikan pada gardu distribusi saat terjadi gangguan. Adapun dari segi Telesignaling yaitu saat pengiriman sinyal notifikasi untuk mengaktifkan proses recovery gardu saat gangguan. Adapun akuisisi data terdapat pada saat penyimpanan data SAIDI SAIFI dan penyimpanan hasil monitoring perangkat. Dari hasil pengujian perangkat keras dan perangkat lunak, terutama dalam pengujian sistem ketika gardu dimatikan, proses pemulihan berjalan sesuai dengan skenario awal. Setelah gardu relay dilanjutkan, data disimpan mengikuti waktu mati, seumur hidup, durasi, dan periode data.
\end{abstract}

Kata kunci: SCADA, Internet of Things (IoT), Fuzzy Mamdani, Telemetering, Telekontrolling, Telesignaling 


\section{PENDAHULUAN}

SCADA adalah sistem yang dapat melakukan proses akuisisi data, kontrol, dan pemantauan sistem kontrol industri [1]. Elemen SCADA terdiri dari tiga bagian, yaitu Perangkat Lapangan, RTU (Remote Terminal Unit), MTU (Master Terminal Unit) [2], [3]. Data dari Perangkat Lapangan dikirim ke RTU (PLC), kemudian dikirim ke MTU. Komunikasi data antara PLC dan MTU menggunakan komunikasi serial RS232C. Data dari MTU akan dikirim ke server [4] [5] [6]. Kelebihan dari sistem SCADA yang diterapkan pada jaringan distribusi jika dibandingkan dengan sistem yang telah ada sebelumnya (konvensional) yaitu dapat memantau, mengendalikan, mengkonfigurasi dan mencatat kerja sistem secara real time (setiap saat),serta mampu menangani gangguan yang bersifat permanen ataupun yang bersifat sementara dalam waktu yang singkat secara remote (jarak jauh) dari pusat kontrol [7] [8] [9] [10].

Model yang diusulkan ini juga dilengkapi dengan SCADA sistem, yang akan memberikan gambaran lebih nyata tentang proses yang terjadi saat trip maupun penanganannya. Untuk lebih memudahkan proses kontrol dan monitoring, maka bentuk dan ukurannya-pun dibuat dalam model miniatur yang mudah dibawa (portable). Model Sistem SCADA ini menggunakan Arduino untuk control. Arduino adalah kit elektronik atau papan rangkaian elektronik open source yang di dalamnya terdapat komponen utama yaitu sebuah chip mikrokontroler [11] [12]. Arduino adalah sistem open source berbasis elektronik yang fleksibel dan mudah digunakan baik dari segi perangkat keras maupun perangkat lunak. Selain itu, kekuatan utama Arduino terletak pada banyaknya pengguna, sehingga terdapat banyak perpustakaan kode program dan modul pendukung. Sehingga memudahkan siswa untuk mengenal dunia mikrokontroler [13].

Model SCADA yang akan dilakukan dengan munggunakan logika fuzzy. Metode logika Fuzzy merupakan suatu metode yang dapat diterapkan pada input data yang berupa variabel linguistik, yaitu variabel yang bersifat alamiah atau diperoleh dari manusia. Output yang diperoleh dengan metode berupa himpunan fuzzy [14] [15] [16]. Logika fuzzy menyediakan mekanisme inferensi yang memungkinkan kita untuk mensimulasikan penalaran manusia ke dalam sistem berbasis pengetahuan. Teori logika fuzzy menyediakan kerangka kerja matematika yang memungkinkan pemodelan ketidakpastian proses kognitif manusia dengan cara yang dapat dipahami oleh komputer [17] [18]. Ada dua alasan penting menggunakan logika fuzzy yaitu (1) data yang diperoleh dari pengukuran sensor mungkin tidak tepat dan tidak sempurna dan (2) logika fuzzy dapat berurusan dengan ketidaktepatan dan ketidakpastian karena sifat kinerja dan kejelasan yang diperlukan untuk proses klasifikasi [19].

\section{METODE PENELITIAN}

Desain sistem yang akan dibuat memiliki beberapa langkah dalam penyelesaiannya. Desain yang dirancang diperlukan agar sistem yang akan diterapkan tidak keluar dari tujuan semula [20]. Metode dalam penelitian ini akan menghasilkan prototipe perangkat keras dan lunak pada sebuah model SCADA yang didukung dengan cara kerja seperti Telemetering, Telestatus, dan Telekontrol yang mengontrol, menghubungkan, dan mendistribusikan Jaringan Tegangan Menengah (JTM). Skenario sistem pada rangkaian alat ini baik hardware maupun software memiliki fungsi alur kerja SCADA pada masing-masing trafo dalam sebuah maket. Pada tahap ini dibuatlah desain model alat dan interface pada aplikasi pengendalian/pemantauan seperti terlihat pada gambar 1 dibawah ini. 


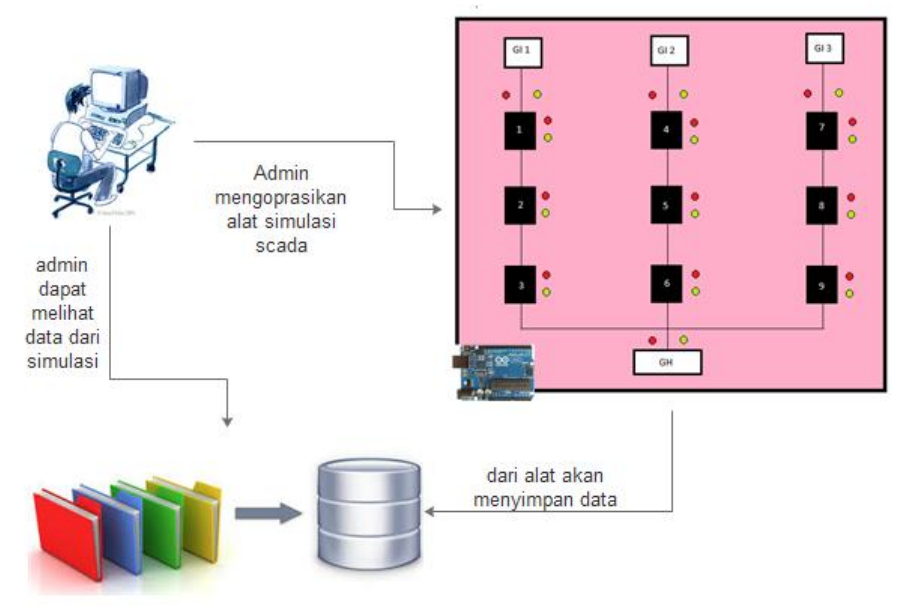

Gambar 1. Skema SCADA: Model Kendali dan Monitoring

Desain aplikasi pemantauan menggunakan teknik inferensi logika fuzzy dengan metode fuzzy Mamdani berdasarkan langkah-langkah berikut:

1) Masukkan Variabel dalam bentuk arus dan tegangan

2) Keluaran variabel dalam bentuk memuat transformer

3) Fuzzy Mamdani Inference dihasilkan dari memasukkan Variabel, Variabel Output, dan Basis Pengetahuan.

4) Basis Pengetahuan berdasarkan 9 Aturan yaitu:

a) [R1] Jika Arus Rendah dan Tegangan Rendah maka Beban Transformer Rendah.

b) [R2] Jika Arus Normal dan Tegangan Rendah, maka Beban Trafo Rendah.

c) [R3] Jika Arus Tinggi dan Tegangan Rendah, Transformer Beban Rendah.

d) [R4] Jika Arusnya Rendah dan Tegangannya Normal, maka Transformer Loading Normal.

e) [R5] Jika Arus adalah Tegangan Normal dan Normal, maka Normal Transformer Loading.

f) [R6] Jika Arus Tinggi dan Tegangan Normal, Pemuatan Transformer Normal.

g) [R7] Jika Arus Rendah dan Tegangan Tinggi maka Load Transformer Tinggi.

h) [R8] Jika Arus Normal dan Tegangan Tinggi, Transformer Beban Tinggi

i) [R9] Jika Arus Tinggi dan Tegangan Tinggi, Transformer Beban Tinggi.

Gambar 2 dibawah ini dapat diketahui proses recovery jika terjadi trip di masing-masing gardu. Jika gardu induk tidak berfungsi maka gardu hubung akan mengaliri listrik pada gardu 3, gardu 2 dan gardu 1. Ketika gardu 1 tidak berfungsi maka gardu hubung akan mengaliri listrik pada gardu 3 dan gardu 2. Ketika gardu 2 tidak berfungsi maka gardu hubung akan mengaliri listrik pada gardu 3 saja. Namun jika gardu 3 tidak berfungsi, maka gardu hubung tidak melakukan recovery. 


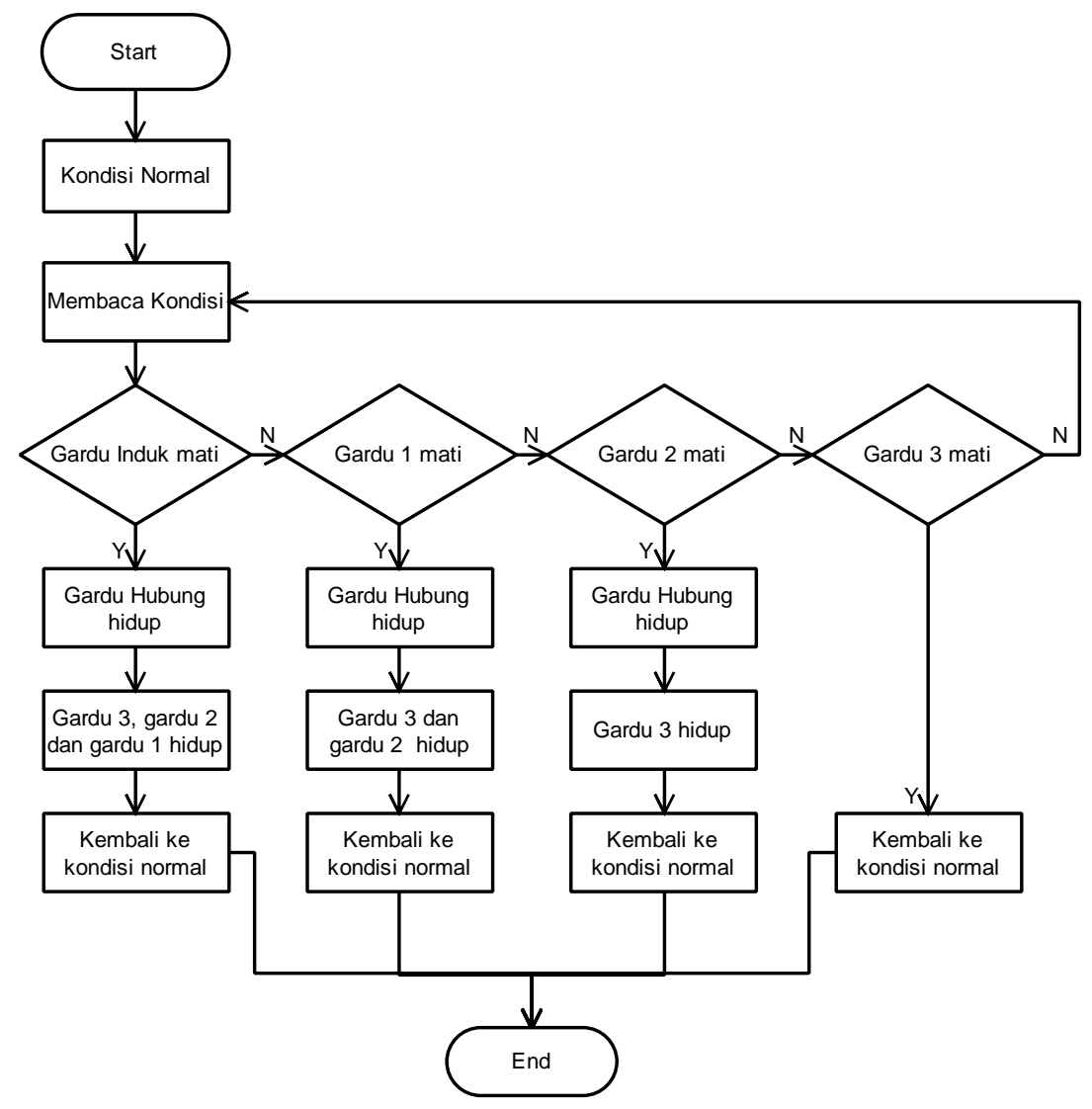

Gambar 2. Flowchart Logika SCADA

\section{HASIL DAN PEMBAHASAN}

Setelah melakukan percobaan atau mengoperasikan, data akan dikumpulkan didalam database. Pemrosesan data yang dikumpulkan akan ditampilkan pada tampilan layar seperti yang terlihat pada gambar 3. Hasil pemrosesan data disebut Saidi dan Saifi. Saidi adalah hasil dari pemadaman yang lama dalam sedetik sementara Saifi berapa banyak pengumpan mengalami gangguan dalam sehari. Batas untuk saidi dan Saifi adalah per detik dan per hari. Hal ini diambil karena mengikuti simulasi yang akan dilakukan secara real-time.

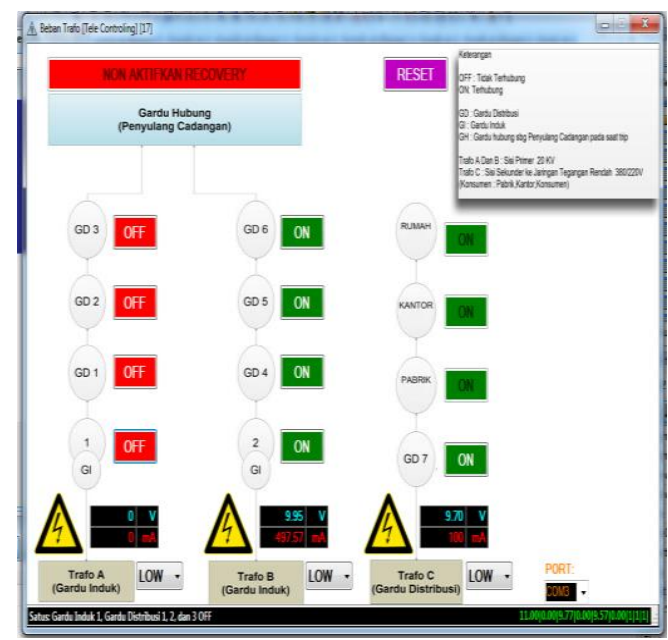

Gambar 3. Antarmuka aplikasi monitoring SCADA 
Dalam sistem sensor pada gambar 4 dibawah ini, metode yang digunakan adalah logika fuzzy Mamdani, ada dua variabel input yaitu arus dan tegangan. Berikut adalah klasifikasi:

- Sekarang: \{Rendah, Normal, Tinggi\}

- Tegangan: \{Rendah, Normal, Tinggi\}

Keluaran:

- Beban Trafo: \{Rendah, Normal, Tinggi\}

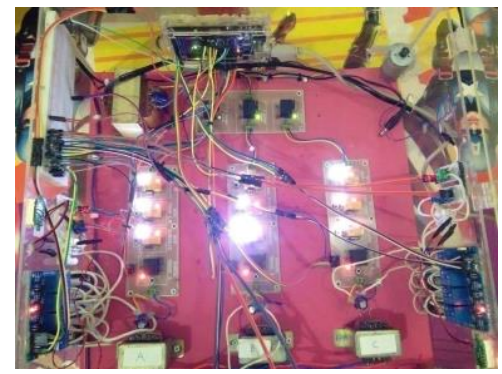

Gambar 4. Simulasi menjalankan SCADA ini:

Untuk Fungsi Keanggotaannya menggunakan rumus kurva trapesium seperti rumus dibawah

$$
[x]\left\{\begin{array}{cc}
0 ; & x \leq \text { a atau } x \geq d \\
(x-a) /(b-a) & ; \quad c<x \leq b \\
1 ; & b<x \leq c \\
(d-x) /(d-c) & c<x \leq d
\end{array}\right.
$$

Rumus (1). Kurva Trapesium

Fungsi keanggotaan dalam logika fuzzy Mamdani telah dibuat berdasarkan variabel arus input dan tegangan. Saat ini untuk arus: Rendah $\{0,600\}$ parameter dibuat $\{0,350,450,600\}$, Normal $\{400-650\}$ parameter dibuat $\{400,500,550,650\}$, parameter Tinggi $\{\geq 600\}$ dibuat $\{600$, 650, 750, 1000\}, ketika menentukan tegangan: rendah $\{\leq 10.5\}$ dari Parameter $\left\{\begin{array}{llll}0 & 4 & 7 & 10.5\end{array}\right\}$, Normal $\{9-14\}$ Parameter $\{9,10,13,14\}$ dan tinggi $\{\geq 13\}$ - Parameter $\{13,14,15,16\}$. Sehingga diperoleh Rules sebagai berikut:

[R1] IF (Arus Rendah) AND (Tegangan Rendah) THEN (Beban Trafo Rendah)

[R2] IF ([Arus Normal) AND (Tegangan Rendah) THEN (Beban Trafo Rendah)

[R3] IF (Arus Tinggi) AND (Tegangan Rendah) THEN (Beban Trafo Rendah)

[R4] IF (Arus Rendah) AND (Tegangan Normal) THEN (Beban Trafo Normal)

[R5] IF (Arus Normal) AND (Tegangan Normal) THEN (Beban Trafo Normal)

[R6] IF (Arus Tinggi) AND (Tegangan Normal) THEN (Beban Trafo Normal)

[R7] IF (Arus Rendah) AND (Tegangan Tinggi) THEN (Beban Trafo Tinggi)

[R8] IF (Arus Normal) AND (Tegangan Tinggi) THEN (Beban Trafo Tinggi)

[R9] IF (Arus Tinggi) AND (Tegangan Tinggi) THEN (Beban Trafo Tinggi)

Sementara untuk menyelesaikan tahap fungsi implikasi untuk setiap aturan pada logika fuzzy mamdani yang digunakan adalah dengan Metode MIN. 
[R5] IF (Arus Normal) AND (Tegangan Normal) THEN (Beban Trafo Normal)

[R6] IF (Arus Tinggi) AND (Tegangan Normal) THEN (Beban Trafo Normal)

[R8] IF (Arus Normal) AND (Tegangan Tinggi) THEN (Beban Trafo Tinggi)

[R9] IF (Arus Tinggi) AND (Tegangan Tinggi) THEN (Beban Trafo Tinggi)

$$
\begin{aligned}
& \mu \text { ArusNormal }[630] \\
& =(20)(100)=0.2 \\
& \mu \text { ArusTinggi }[630] \\
& =(30)(50)=0.6 \\
& \mu \text { TeganganNormal }[13.23] \\
& =(0.77)(1)=1 \\
& \mu \text { TeganganNormal }[13.23] \\
& =(0.23)(1)=1
\end{aligned}
$$

$\alpha$-predikat (fire strength) untuk setiap aturan sebagai berikut :

[R5] IF (Arus Normal) AND (Tegangan Normal) THEN (Beban Trafo Normal)

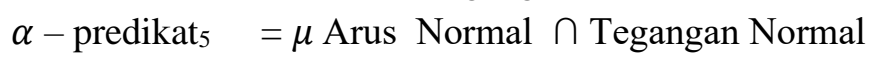$$
=\min (\mu \text { ArusNormal }(630), \mu(\mu \text { Tegangan Normal }(13.23))
$$

$$
\begin{aligned}
& =\min (0.2 ; 0.77) \\
& =0.2
\end{aligned}
$$

[R6] IF (Arus Tinggi) AND (Tegangan Normal) THEN (Beban Trafo Normal)

$$
\alpha-\text { predikat }_{6}=\mu \text { Arus Tinggi } \cap \text { Tegangan Normal }
$$$$
=\min (\mu \text { Arus Tinggi }(630), \mu(\mu \text { Tegangan Normal(13.23) })
$$$$
=\min (0.6 ; 0.77)
$$

$$
=0.6
$$

[R8] IF (Arus Normal) AND (Tegangan Tinggi) THEN (Beban Trafo Tinggi)

$$
\begin{aligned}
\alpha-\text { predikat }_{8} & =\mu \text { Arus Normal } \cap \text { Tegangan Tinggi } \\
& =\min (\mu \text { Arus Normal }(630), \mu(\mu \text { Tegangan Tinggi }(13.23)) \\
& =\min (0.2 ; 0.23) \\
& =0.2
\end{aligned}
$$

[R9] IF (Arus Tinggi) AND (Tegangan Tinggi) THEN (Beban Trafo Tinggi)

$$
\begin{aligned}
\alpha-\text { predikat }_{9} & =\mu \text { Arus Normal } \cap \text { Tegangan Normal } \\
& =\min (\mu \text { Arus Normal }(630), \mu(\mu \text { Tegangan Normal }(13.23)) \\
& =\min (0.6 ; 0.23) \\
& =0.23
\end{aligned}
$$

Proses selanjutnya adalah hasil fungsi implikasi dari tiap aturan, digunakan metode MAX untuk komposisi antar semua aturan. Hasilnya dapat dilihat seperti gambar 5 dibawah ini. 


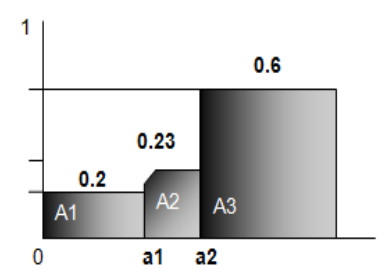

Gambar 5. Komposisi Antar Aturan

Hasil pengujian dengan aplikasi Matlab ditunjukkan pada Gambar 6 dibawah ini. Dari 9 Aturan untuk menguji output arus input yang mengandung transformator dan sensor tegangan, hasil yang diperoleh dalam aturan [8] dengan inferensi IF (Arus Normal; (630) DAN Tegangan (Tinggi); (13.2) TRAFFIC) (Beban Trafo Tinggi).

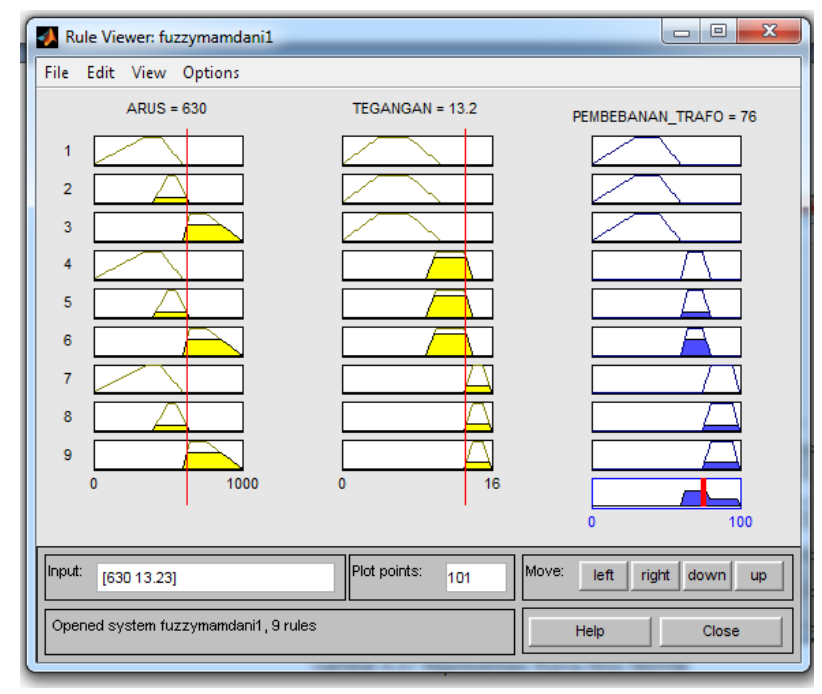

Gambar 6. Tampilan Hasil R[8] di aplikasi Matlab

\section{KESIMPULAN DAN SARAN}

Penerapan logika fuzzy Mamdani ke media pembelajaran Pengantar Teknologi SCADA adalah aspek telemetri. Penyelesaian logika fuzzy Mamdani dibuat dalam 3 tahap, yaitu pembentukan logika fuzzy Mamdani, penerapan fungsi implikasi, dan metode max. Sistem pemantauan kondisi beban transformator dibuat dengan mengukur arus dan tegangan melalui sensor secara real-time ke transformator dalam sistem distribusi. Berdasarkan hasil uji Aturan Logika Mamdani pada output arus input yang mengandung transformator dan sensor tegangan, hasilnya diperoleh dalam aturan [8] dengan inferensi IF (Arus Normal; (630) DAN Tegangan (Tinggi); ( 13.2) TRAFFIC) (Beban Trafo Tinggi). Hasil desain inferensi logika fuzzy Mamdani pada beban distribusi informasi gardu induk pada kondisi beban trafo Rendah, Normal, dan Tinggi, dimana nantinya siswa dapat memahami tindakan apa yang seharusnya dilakukan. diambil dalam kondisi ini, khususnya, dapat mempertimbangkan pemeliharaan transformator.

\section{UCAPAN TERIMA KASIH}

Penulis mengucapkan terima kasih kepada Institut Teknologi PLN yang telah memberi dukungan pendanaan dan bantuan dalam pelaksanaan penulisan artikel. Penulis juga berterima kasih kepada para reviewer anonim atas komentar mereka yang berharga untuk merevisi makalah ini. 


\section{DAFTA PUSTAKA}

[1] T. Cruz et al., "A Cybersecurity Detection Framework for Supervisory Control and Data Acquisition Systems," IEEE Trans. Ind. Informatics, vol. 12, no. 6, pp. 2236-2246, 2016.

[2] A. Ghaleb, S. Zhioua, and A. Almulhem, "SCADA-SST: A SCADA security testbed," in 2016 World Congress on Industrial Control Systems Security, WCICSS 2016, 2017, pp. 34-39.

[3] P. S. S. Shah, S. Raut, D. Jagadale, A. Khatmode, and H. Patil, "IOT Based Industrial SCADA System,” Int. Res. J. Eng. Technol., vol. 4, no. 4, pp. 2432-2435, 2017.

[4] Y. Chen and W. Pei, "Design and implementation of SCADA system for micro-grid," Inf. Technol. J., vol. 12, no. 24, pp. 8049-8057, 2013.

[5] B. Atlagic, M. Cokic, and M. Ssagi, "Concept of a SCADA system designed for education and research," Appl. Microbiol. Biotechnol., vol. 85, no. 1, pp. 2071-2079, 2014.

[6] M. S. Thomas and J. D. McDonald, "SCADA fundamentals," in Power System SCADA and Smart Grids, 2015, pp. 21-74.

[7] L. A. Maglaras and J. Jiang, "Intrusion detection in SCADA systems using machine learning techniques," in Proceedings of 2014 Science and Information Conference, SAI 2014, 2014, pp. 626-631.

[8] A. Ujvarosi, "Evolution of SCADA Systems," Bull. Transilv. Univ. Braşov, vol. 9, no. 58, pp. 63--68, 2016.

[9] R. H. McClanahan, "The benefits of networked scada systems utilizing IP-enabled networks," in Papers - Rural Electric Power Conference, 2002, pp. C5-1.

[10] M. A. A. Ias G.I., Lolea M.S., "Scenarios Of Regional Power System Expansion From Southern Of Bihor County Based On The Exploitation Of Renewable Energy Sources," J. Sustain. ENERGY, vol. 9, no. 2, pp. 93-100, 2018.

[11] I. Allafi and T. Iqbal, "Low-Cost SCADA System Using Arduino and Reliance SCADA for a Stand-Alone Photovoltaic System," J. Sol. Energy, 2018.

[12] K. S. Budi, S. Muslim, and A. B. Santosa, "Literature Study on the Influence of Arduino Microcontroller Trainer Media on Creative Thinking Level and Student Learning Outcomes in Microcontroller Learning," in International Symposium on Social Sciences, Education, and Humanities (ISSEH 2018), 2019.

[13] S. S. M. Setiawan Agus, "Simulasi Mikrokontroler Pengukur Jarak Berbasis Arduino Uno Sebagai Media Pembelajaran Mahasiswa Politeknik Harapan BersamA,” J. POLEKTRO J. Power Elektron., 2018.

[14] K. E. Holbert, A. Mishra, and L. Mill, "Intrusion detection through SCADA systems using fuzzy logic-based state estimation methods," Int. J. Crit. Infrastructures, 2007.

[15] Z. Aydogmus, "Implementation of a fuzzy-based level control using SCADA," Expert Syst. Appl., 2009.

[16] J. H. Horng, "SCADA system of DC motor with implementation of fuzzy logic controller on neural network," Adv. Eng. Softw., 2002.

[17] P. Pancardo, J. A. Hernández-Nolasco, and F. Acosta-Escalante, "A Fuzzy Logic-Based Personalized Method to Classify Perceived Exertion in Workplaces Using a Wearable Heart Rate Sensor," Mob. Inf. Syst., vol. 2018, 2018.

[18] L. A. Zadeh, "Outline of a New Approach to the Analysis of Complex Systems and Decision Processes," IEEE Trans. Syst. Man Cybern., 1973.

[19] H. Medjahed, D. Istrate, J. Boudy, and B. Dorizzi, "Human activities of daily living recognition using fuzzy logic for elderly home monitoring," in IEEE International Conference on Fuzzy Systems, 2009. 
[20] Budiana ND, Siregar RR, Susanti MN. Penetapan Instruktur Diklat Menggunakan Metode Clustering K-Means dan Topsis Pada PT PLN (Persero) Udiklat Jakarta. PETIR: Jurnal Pengkajian dan Penerapan Teknik Informatika. 2019 Aug 6;12(2):111-21.

[21] Siswipraptini PC, Aziza RN, Sangadji IB, Indrianto I, Siregar RR. Automated Smart Home Controller Based on Adaptive Linear Neural Network. In2019 7th International Conference on Control, Mechatronics and Automation (ICCMA) 2019 Nov 6 (pp. 423-427). IEEE.

[22] E. Kamel and A. M. Memari, "State-of-the-Art Review of Energy Smart Homes," J. Archit. Eng., vol. 25, no. 1, p. 03118001, 2019.

[23] Siregar RR, Sikumbang H, Sangadji IB. KWh Meter Smart Card Model Token For Electrical Energy Monitoring. InMATEC Web of Conferences 2018 (Vol. 218, p. 03002). EDP Sciences. 